DOI: $10.22616 /$ REEP.2019.003

\title{
Critical Evaluation of Personality Traits and Behavioural Gender Peculiarities of Latvian Males and Females
}

\author{
Jeḷena Badjanova ${ }^{1}$ Dr. paed.; Dzintra Ilisko ${ }^{2} \mathrm{PhD}$; Svetlana Ignatjeva ${ }^{3}$ Dr. physics \\ Daugavpils University, Latvia \\ jelena.badjanova@du.lv¹; dzintra.ilisko@du.lv²; svetlana.ignatjeva@du.lv³
}

\begin{abstract}
The topicality of this study is determined by a growing interest in gender studies in all fields of science. For the purpose of this particular study, the authors have analysed the peculiarities of males and females in the context of androgyny theory. The aim of the study is to explore how Domination and Submission determine the behavioural patterns and dynamics of Latvian males and females. The research was based on quantitative research methodology. The authors adapted a methodology by Leary, Leforge and Sazek. The number of research participants was 204, the participants represent different regions of Latvia and three age groups varying from 19 to 62 years old. Empirical research that was carried out in 2016-2017 has revealed the traits and the dynamics of gender behaviour of Latvian males and females. The authors have measured the scale of masculinity and femininity among the research participants. It was discovered that in all groups of research participants, namely, in the age groups ranging from 18 to 60 years old, both males and females display high level of androgyny. Research results demonstrated head apt ability of the inhabitants of Latvia in the changing socio-economic conditions. As a result of constructing models of male and female social behaviour, it was concluded that a values system determined by societal and cultural conditioning and accepted social norms is of a crucial importance. The theoretical basis of this research is grounded in classical theories and the latest research in the field. As a follow-up research, the authors have explored such gender traits as Domination, Submission and Altruism.
\end{abstract}

Keywords: personality traits, characteristics of male and female behaviour and their dynamics, psychology.

\section{Introduction}

Formation of a gender identity is a topical issue in Latvia and abroad. Many researchers (Bordo, 1990; Rustin, Foels, 2012) report that during the last 20 years, the main focus of attention is on how sociocultural norms determine male and female's psychological peculiarities, models of behaviour and professions. A high index of androgyny was detected with the inhabitants of Latvia during the survey conducted in 2016 -2017, which was realised according to S.L. Bem's (1974) concept of gender role and the results of BSRI (Bem Sex-Role Inventory) (Badjanova, Ilisko, Petrova, 2018).

S. Bordo (1990) emphasises that politics influences the formation of identity. Identity is characterised by such determinants as gender and sexuality. There are new types of identity emerging with ,unbalanced” or not constant gender characteristics which do not correspond to cultural norms that traditionally define a personality. S.L. Bem (Bem, 1998) emphasises that mechanisation and economic crises makes it more difficult for males to define their identity financially. To define men's identity by their financial status means defining them as losers. The traditional gender roles no longer serve as main gender characteristics.

In order to understand the influence of the environment on gender behaviour, U. Bronfenbrenner (1979) suggests a system theory and its emphasis on a socio-cultural approach to the development of an individual and points to five subsystems that interrelates among them. Social interactions take place in a micro-system and determine the development of individual's self-understanding (Santrock, 2011).

The relationships with peers and adults are some of the most significant influences. The mesosystem involves relationships with micro- and macro-systems, for instance, the relationships between family experience and mass media. The macro-systems in involve a cultural influence irrespective of the size of the group, thus influencing the identity, knowledge, social behaviour and ethnic belonging. The chrono-system involves significant events and changes in the life of an individual, as well as sociohistorical conditions.

By the analyses of diverse aspects of male and female behavioural models, S.M. Burn (2014) determines the content of social constructivist theory that is based on the following premises: (1) gender is constructed by socialisation, gender role system, and the influence of family and mass media; (2) gender 
is constructed on a level of consciousness by accepting the norms determined by the society in regards to appearance and manner of behaviour. Any individual can change his/her behaviour in adjusting it to societal norms. This kind of behaviour can be considered as submissive, involving one's willingness to escape from societal punishment and/or gain societal approval. This is a normative type of behaviour. Therefore, male and female model of behaviour is expanded by the following notions.

- Compliance. Compliance to societal norms. Person does not accept them but acts in order to escape from punishment and earn societal recognition.

- Acceptance. Submissiveness to societal norms.

- Identification. Compliance to societal norms when a person emulates a role model.

Contemporary theories (Walsh, 2001; Lips, 2014) reveal not only a difference in status, role and other aspects of male and female life conditions, but also the analyses on domination and power issues that are transferred by the main gender roles and relationships. Gender is defined as the societal positions and individual characteristics that are viewed as characteristic to males or females. Gender role identifications are related role identifications and a number of components of gender stereotypes: personality traits, role behaviour, profession, and physical appearance.

Among the gender differences, there is no indication of leadership. Researchers (Bem, 1998; Rustin, Foels, 2012; Racene, 2013) draw attention to the fact that more and more of contemporary women carry a financial responsibility for their families. Psychologists point to minor differences that exist between male and female behaviour and highlight the similarities. The notion of androgyny is developed when a person displays both feminine and masculine characteristics depending on the situation. Therefore, the issue of male and female gender similarities and differences remains open for discussion.

The following section of the article will present and discuss the next stage of research with the proposed aim: to explore the peculiarities of Latvian male and female personality traits across three age groups and comparatively analyse the obtained results against the findings of a previous study on male and female behavioural gender peculiarities.

\section{Methodology}

Non-experimental research design was used in this quantitative study, which was conducted in 2018 in real life environment in different regions of Latvia. Two research questions were proposed: (1) are there any differences between male and female personality traits in youth, early and mid-maturity age groups? (2) how can personality traits impact male and female behavioural gender peculiarities in early and mid-maturity ages?

Within the structure of empirical research design a research instrument was created to study Latvian female and male personality traits: a questionnaire of Leary, Lefroge and Sazek was adapted. The questionnaire contained 128 statements (Leary, 1954; Ilyin, 2008, 411-413). The questionnaire was designed with an aim of determining such personality traits as Dominance, Submission and Altruism among females and males from Latvia, which have a major significance in decision making, either through relying on one's own opinion or submitting to others, and the similarities and differences in corresponding behavioural patterns across the age groups of youth, early and mid- maturity. The methodology included instruction, answer form and recommendations for data processing and interpretation. The obtained data were quantitative. Quantitative and comparative analysis of the empirical data was performed by using the SPSS (Statistical Package for Social Science) data processing programme, version 20.00.

The research was conducted with 204 respondents $(N=204(100 \%))$ in 2018. Of those, 134 were women $(n$ $=134(65.7 \%))$ and 70 were men $(n=70(34.3 \%))$. That study included participants belonging to three age groups from 18 to 60 years of age. The first group of respondents was made up of men and women aged 19 to $20(n=35(17.2 \%))$; the second group of respondents was comprised of men and women aged 21 to 25 $(n=53(26 \%))$; the third group of respondents included men and women aged 26 to $62(n=116(56.9 \%))$.

In the course of research, in order to detect the characteristically male and female personality traits in response to the first question, during the first stage of data processing eight scales determining the personality type were singled out and the total value was calculated for each scale separately. According to the methodology, the mean value of the first four scales pertains to Domination, the mean value of the following three scales pertains to Submission, but the eighth scale - to Altruism. In addition, the Degree of Expression was determined for each separate scale. 


\section{Results and Discussion}

The distribution of Domination, Submission and Altruism according to the Kolmogorov-Smirnov test both gender groups showed no significant deviation from the normal distribution, which allows for the application of Student's t-test in comparing these quantitative indicators.

Domination for women varies from 1.75 to 11.5 in relation to Mean (Mean $=6.78$; Range $=9.75 ;$ Std . Deviation $=2.04)$. For males, this indicator is in a range from 1.75 to 13.75 (Mean $=7.61 ;$ Range $=12$, Std. Deviation = 2.19). The Mean of Submission for women is - $8.00($ Mean $=8.00)$, but for men is $6.69($ Mean $=6.69)$. Altruism for women is -9.93 (Mean =9.93), but for men is - $7.93($ Mean = 7.93). The levels of statistical significance of Student's criterion for all three indicators was less than $5 \%$, consequently, we can observe statistically significant differences between male and female genders. Domination has a higher value with men, Submission and Altruism with women (Figure 1).

With both men and women, we observe direct significant correlations of mean power between Submission and Altruism $\left(R^{2}=0.588\right.$ with women and $R^{2}=0.610$ with men). With women all three indicators differ statistically significantly (Paired Samples Test, Sig. $<0.001$ ): Dominance has the lowest value whereas Altruism - the highest. With men, no significant difference can be observed between Domination and Altruism (Paired Samples Test, Sig. < 0.537), while Submission has the lowest value out of all three indicators and significantly differs in measure from both Domination and Altruism.

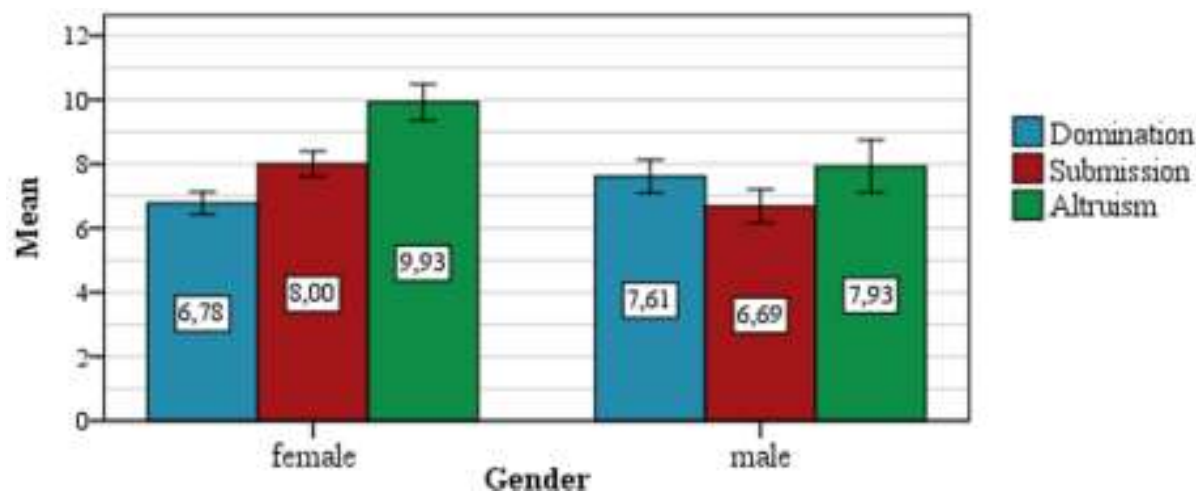

Figure 1. Mean values of Domination, Submission, Altruism with male and female respondents.

According to Kolmogorov-Smirnov test, the distribution of Domination, Submission and Altruism in all three age groups showed no significant deviation from the normal distribution. The normal distribution is the most important and most widely used distribution in statistics. An assessment of the normality of data is a prerequisite for many statistical tests because normal data is an underlying assumption in parametric testing. Normal distributions are symmetric around their mean. The mean, median, and mode of a normal distribution are equal. Normal distributions are defined by two parameters, the mean and the standard deviation. Many classical statistical tests (Student's t-test, one-factor analysis of variance ANOVA) are based on the assumption that the data follow a normal distribution. We usually use Kolmogorov-Smirnov test to check the normality assumption.

To estimate the impact of age on these indicators, we used the one-factor analysis of variance ANOVA (Domination: $F=5.037$, Sig. $=0.007$; Submission: $F=2.343$, Sig. $=0.099$; Altruism: $F=7.730$, Sig. $=0.001)$. According to the F-criterion, age has a statistically significant impact on Domination and Altruism. Domination has the lowest value in the age group of 26 to 62 years old. In the age groups of 19 to 20 and 21 to 25 years old Domination has no statistically significant differences (Bonferroni criterion, Sig. $=0.010)$. Altruism in these age groups also shows no significant differences in value whereas in the age group of 26 to 62 years old it is significantly higher. Submission has the lowest value in the age group of 21 to 25 years old and the highest value in the age group of 26 to 62 years old, although these differences are no statistically significant. In all age groups we can observe statistically significant direct correlations between Submission and Altruism. According to the Paired Samples Test, in the age group of 19 to 20 years old we observe no statistical difference between Domination, Submission and Altruism. In the age group of 26 to 62 years old Domination has the lowest value and Altruism the highest, and these differences are statistically significant. With that, the differences between Domination-Submission and Submission-Altruism in this age group are also statistically 
significant. In the age group of 21 to 25 years old Submission has the lowest score and Altruism the highest, yet the difference between Domination and Altruism is not statistically significant (Figure 2).

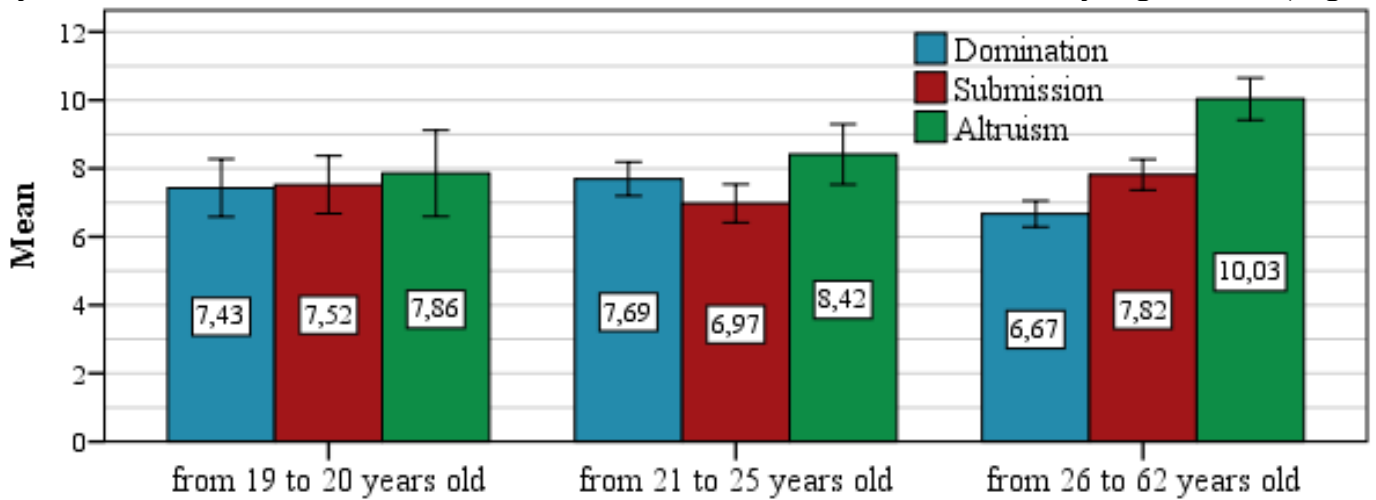

Age group

Figure 2. Mean values of Domination, Submission, Altruism with respondents of different age groups.

Figure 3 illustrates how Dominance is impacted by the two factors of age and gender. In all age groups the values of Dominance with men are higher than with women, yet in the age group of 26 to 62 years old this difference is not statistically significant $(T$-test, Sig. $=0.014)$. With men we observe no impact of age on Domination (ANOVA, Sig. $=0.751$ ), whereas with women Domination decreases with age, and this impact is statistically significant (ANOVA, Sig. $=0.011$ ).

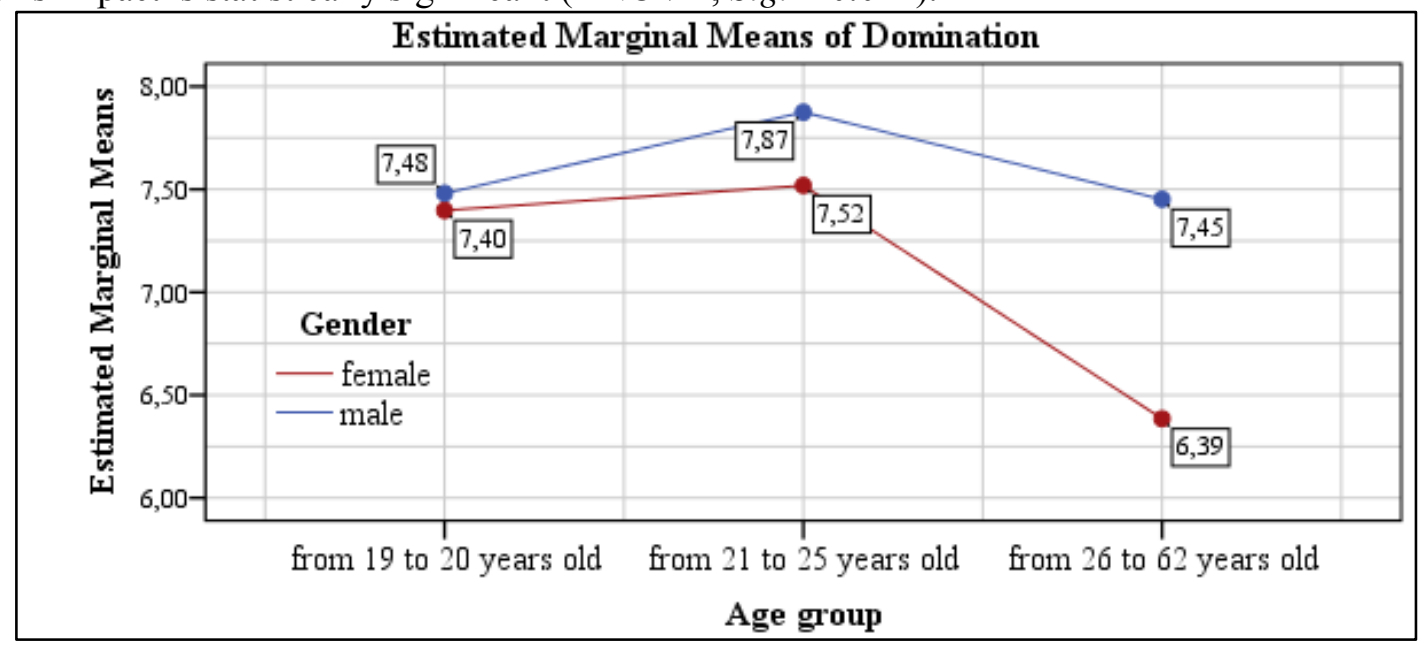

Figure 3. Estimated marginal means of Domination with male and female respondents of different age groups.

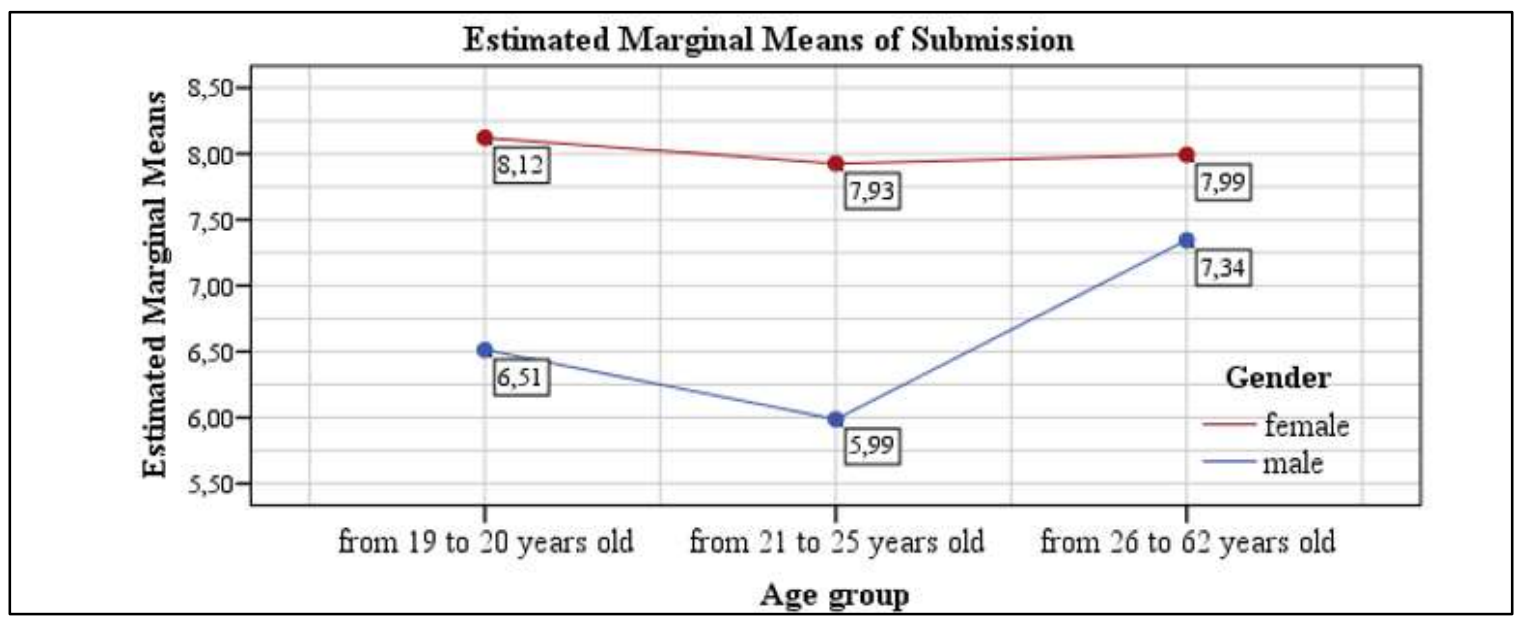

Figure 4. Estimated marginal means of Submission with male and female respondents of different age groups. 
Submission (Figure 4) in all age groups has higher values with women than with men, yet in the age group of 26 to 62 years old this difference is not statistically significant $(T$-test, Sig. $=0.210)$. Age has no significant impact on Submission either for women or for men (ANOVA, Sig. > 0.05).

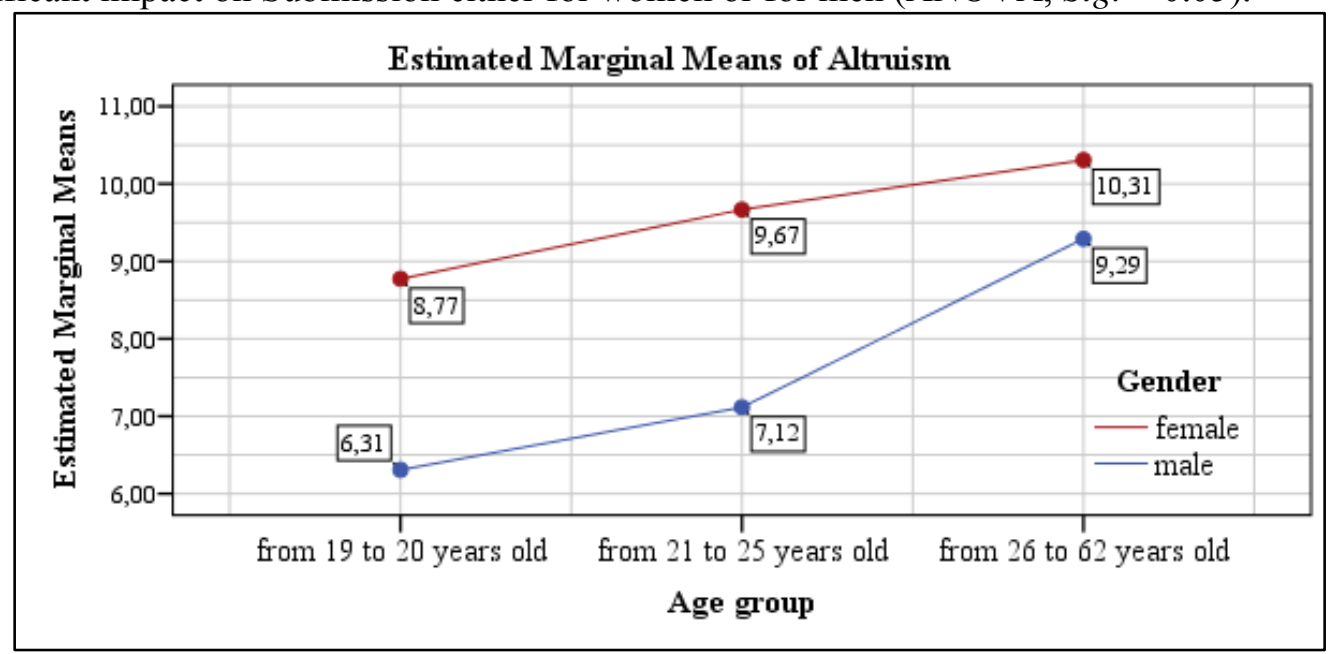

Figure 5. Estimated marginal means of Altruism with male and female respondents of different age groups.

In all age groups (Figure 5) the values of Altruism are higher with women than with men, yet in the age group of 26 to 62 years old this difference is no longer statistically significant $(T$-test, Sig. $=0.150)$. With women age has no significant impact on Altruism (ANOVA, Sig. $=0.142$ ), whereas with men this impact is statistically significant (ANOVA, Sig. $=0.008$ ).

\section{Conclusion}

The results of empirical research yielded the essential traits characteristic of male and female personality. In response to the first research question of whether there are any similarities of differences between male and female personality traits in the youth, early and mid-maturity age groups we can conclude that in all age groups Domination values among men are higher than among women, whereas Submission and Altruism values with women are higher than with men. Hence the conclusion that gender indeed determines certain differences in male and female personality traits.

Regarding the impact of age on manifestations of male and female personality traits, we can conclude the following:

- in the age group of 19 to 20 years old, statistically significant differences can be discerned in the manifestation of Altruism, that being higher with women than with men; men display more Dominance while women demonstrate higher rates of Submission;

- in the age group of 21 to 25 years old, no statistically significant difference was discerned. Yet, in this age group women show slightly higher rates of Dominance than in the first age group;

- in the age group of 26 to 62 years old, Domination has the lowest significance whereas Submission and Altruism - the highest, and these differences are statistically significant. With regard to the impact of age on the intensity of personality traits, we can conclude that age has no impact on manifestations of Dominance in men, the scores are similar in youth, early and mid-maturity age groups. With women, on the contrary, there is a difference - the older a woman, the less intensive manifestations of Domination in her, and this age impact if statistically significant. However, age has no impact on the category of Submission, with no statistically significant differences both in men and women. In all age groups from youth to early and mid-maturity Submission rates are higher for women than for men, with no statistically significant difference between the sexes in the age group of 26 to 62 years old.

This, irrespective of the gender, age has a statistically significant impact only on the parameters of Dominance and Altruism: in women the intensity if Dominance drops significantly with age, whereas the intensity of Altruism grows. In all age groups Submission rates do not display any statistically 
significant differences: it is more manifested in women than in men, but the age has no impact on its intensity. Practically, with men no statistically significant difference can be observed. With women there is a difference, but not as significant. In order to answer the second research question - how can personality traits impact male and female behavioural gender peculiarities in early and mid-maturity age groups - masculinity was initially interpreted as a parameter of the personality trait of Dominance, but femininity as a parameter of the personality traits of Submission and Altruism.

According to the obtained research results, we can conclude that in the youth age group (19 to 20 years old) personality traits have no impact on behavioural gender peculiarities of either males or females, as opposed to early ( 21 to 25 years old) and mid-maturity ( 26 to 62 years old) age groups, where women of the early-maturity age and men of mid-maturity age display androgyny (Dominance for women and Altruism for men). It can be established that according to previous research results the indices of masculinity and femininity were more or less similar in youth and early-maturity age groups, whereas in the mid-maturity age group both men and women displayed high rates of androgyny. It was also concluded that age in particular had an impact on the high indices of androgyny. This year, the research results also reveal that regardless of the fact that in all age groups the intensity of Altruism is higher in women that in men, men aged 26 to 62 years old display the highest intensity rate of Altruism (androgyny) as compared to the previous age groups. In women, on the contrary, this age group displayed a drop in the intensity of Dominance (androgyny) while in the early-maturity age group the intensity of Dominance (androgyny) was higher. Minor differences from previous research results may be observed.

Thus, the index of androgyny and personality traits is closely related only in the second age group for women and in the third age group for men. It proves that personality traits can have a partial impact on behavioural gender peculiarities. Hence, the conducted study of Latvian female and male personality traits enables us to conclude that they had a discernible impact on male and female behavioural gender peculiarities only in the early and mid-maturity age groups. This aspect can be interpreted as follows: only age rather than gender can affect personality's capacity for adaptivity in the changing life conditions. This aspect warrants further and more in-depth study.

\section{Bibliography}

1. Badjanova J., Ilisko Dz., Petrova M. (2018). Definition and Dynamics of Gender-Specific Behaviours of Latvian Males and Females. In V. Dislere (Ed.), The Proceedings of the International Scientific Conference Rural Environment. Education. Personality (REEP), 11. Jelgava: LLU TF, 53-57. Retrieved from

http://llufb.1lu.lv/conference/REEP/2018/Latvia_REEP_2018_proceedings_ISSN2255808X-53-57.pdf

2. Bem S.L. (1974). The Measurement of Psychological Androgyny. Journal of Consulting and Clinical Psychology, 42 (2), 155-162.

3. Bem S.L. (1998). An Unconventional Family. New Haven, CT, US: Yale University Press.

4. Bordo S. (1990). Feminism, Postmodernism, and Gender-Scepticism. In L. Nicholson (Ed.). Feminism/Postmodernism. New York and London: Routledge,133-156.

5. Bronfenbrenner U. (1979). The ecology of human development. Cambridge, MA: Harvard University Press.

6. Burn S.M. (2014). Women across cultures: A global perspective. (3rd ed.). New York: McGraw-Hill.

7. Ilyin E.P. (2008). Motivation and motives. Saint-Petersburg: PETER.

8. Leary T.F. (1954). Leary test. TEST4U International tests ONLINE free. Retrieved from http://test4u.online/en/?view $=$ cat\&category $=40 \#$

9. Lips H.M. (2014). Gender: The basics. Abingdon, Oxon: Routledge.

10. Racene A. (2013). Factors Determining Successful Women Careers. In V. Dislere (Ed.), The Proceedings of the International Scientific Conference Rural Environment. Education. Personality (REEP), 6. Jelgava: LLU, 138-145. Retrieved from http://lufb.llu.lv/conference/REEP/2013/LatviaUniv-Agricult_REEP_2013_ISSN_2255-808X-138-145.pdf

11. Rustin B., Foels R. (2012). Gender Differences in the Need to Belong: Different Cognitive Representations of the Same Social Groups. Current Research in Social Psychology. Retrieved from https://uiowa.edu/crisp/sites/uiowa.edu.crisp/files/art8.20.14_4.pdf

12. Santrock J.W. (2011). Educational Psychology. ( $5^{\text {th }}$ ed.). New York: McGraw-Hill.

13. Walsh C. (2001). Gender and Discourse: Language and Power in Politic, the Church and Organizations. ( ${ }^{\text {st }}$ ed.). London: Longman. 